\title{
GS/pan-Notch Inhibitor BMS-986115
}

National Cancer Institute

\section{Source}

National Cancer Institute. GS/pan-Notch Inhibitor BMS-986115. NCI Thesaurus. Code C118573.

An orally bioavailable, gamma secretase (GS) and pan-Notch inhibitor, with potential antineoplastic activity. Upon administration, GS/pan-Notch inhibitor BMS 986115 binds to GS and blocks the proteolytic cleavage and release of the Notch intracellular domain (NICD), which would normally follow ligand binding to the extracellular domain of the Notch receptor. This prevents both the subsequent translocation of NICD to the nucleus to form a transcription factor complex and the expression of Notch-regulated genes. This results in the induction of apoptosis and the inhibition of growth of tumor cells that overexpress Notch. Overexpression of the Notch signaling pathway plays an important role in tumor cell proliferation and survival. The integral membrane protein GS is a multisubunit protease complex that cleaves single-pass transmembrane proteins, such as Notch receptors, at residues within their transmembrane domains and leads to their activation. 